Antoine Roch

\title{
Increased levels of pro-AVP and pro-ADM in septic shock patients: what could it mean?
}

Received: 26 May 2009

Accepted: 29 June 2009

Published online: 7 August 2009

(C) Springer-Verlag 2009

This editorial refers to the article available at: doi:10.1007/s00134-009-1610-5.

\section{A. Roch (『)}

Service de Réanimation Médicale, Hôpitaux Sud, 270, boulevard de Sainte Marguerite,

13274 Marseille Cedex 9, France e-mail: antoine.roch@ap-hm.fr

Tel.: +33-491-744948

Although the incidence of septic shock increases over years, its mortality rate remains unacceptable. During septic shock, severe alterations of the cardiovascular system participate in refractory hypotension and multiorgan failure, leading to death. Therefore, the measurement of biomarkers reflecting and/or involved in cardiovascular disturbances is highly attractive to better understand the mechanisms of septic shock, to stratify the risk of death and also to define future therapeutic targets.

Arginine vasopressin (AVP), a hormone synthesized in the hypothalamus, is released by increased plasma osmolality, decreased arterial pressure, and reductions in cardiac volume [1]. When released in the circulation, AVP contributes to fluid homeostasis and induces vasoconstriction. It is cosynthetized with pro-AVP (also known as copeptin), both derived from their larger precursor prepro-AVP. In human septic shock, a biphasic secretion pattern of AVP is observed, characterized by an initial increase followed by a decrease afterward [2, 3]. Moreover, as observed for other stress hormones like cortisol, a relative AVP deficiency has been observed in late septic shock patients that could participate in hemodynamic failure and prognosis [2]. Therefore, although high levels of AVP or pro-AVP have been measured in infected patients $[4,5]$, it is still questioned whether high levels of these hormones or, at the opposite end, relatively low levels, are associated with prognosis during the course of septic shock. Adrenomedullin (ADM) is mainly released from endothelial cells. Unlike AVP, it notably exhibits vasodilation and natriuretic properties [6]. Although the secretion of ADM or its cosynthetized peptid pro-ADM is also increased during sepsis [7, 8], the mechanisms of their overproduction are unclear. Indeed, like other calcitonin peptides such as procalcitonin, ADM gene upregulation is also stimulated by bacterial endotoxins and pro-inflammatory cytokines [9]. AVP and ADM are supposed to have opposite mechanisms of secretion and opposite effects on hemodynamics. This reinforces the interest in studying their respective production kinetics in septic shock patients.

In this issue of Intensive Care Medicine, Dr. Guignant and coworkers [10] measured pro-AVP and pro-ADM levels during the first week of septic shock. Their 99 patients mainly presented with pulmonary or abdominal sepsis, and 28-day mortality was 35\%. The measured levels of pro-AVP and pro-ADM appeared much higher than reported in healthy individuals. Although no control group has been studied, this result suggests an increased secretion of these markers in septic shock patients. Pro-AVP levels were the highest early after shock initiation with a decrease afterward. Pro-AVP levels were higher in non-survivors and exhibited the best prognostic value at day 1-2 and at day 3-4 of shock. Later, pro-AVP levels were not very different between survivors and nonsurvivors, which could reflect a secondary AVP deficiency in the latter, as suggested by other authors [2, 11]. Pro-ADM levels were also higher in non-survivors, but the prognostic value of this marker increased with time, 
unlike for pro-AVP. Future works should clarify whether the relative increase of pro-ADM with time in non-survivors results from an upregulation of pro-ADM secretion in patients with prolonged hemodynamic failure and/or with unresolved infection or if it results from its accumulation in patients with renal failure. The measurement of pro-AVP and pro-ADM level is more suitable in the clinical practice because of their longer half-lives. Additionally and unlike vasopressin, pro-AVP has very high in vitro stability and is less bound to platelets in plasma. However, the progressive renal dysfunction often observed in non-survivors of septic shock may increase pro-AVP and pro-ADM levels by affecting their clearance and consequently bias their prognostic significance after several days of evolution. In this sense, a correlation was found between pro-ADM and creatinine levels in a previous study in septic patients [8]. Moreover, continuous veno-venous hemofiltration was also shown to influence the correlation between AVP and pro-AVP plasma levels [11]. Interestingly, the prognostic value of pro-AVP and pro-ADM was not affected by creatinine level in the study of Dr Guignant et al. [10]. However, the implication of renal dysfunction has not been extensively studied.

An interesting issue is the potential use of biomarkers reflecting hemodynamic and cardiac disturbances to guide hemodynamic management of septic shock. Future works should also determine if the production of pro-AVP and pro-ADM is correlated with cardiac insufficiency and with the intensity of the hemodynamic failure during septic shock.

Apart from pro-AVP and pro-ADM, other biomarkers have been shown to have a prognostic significance during sepsis, such as procalcitonin [12] or the natriuretic peptides ANP and BNP and their respective cosynthetized peptides pro-ANP and pro-BNP [13, 14]. However, only few studies combined different biomarkers to improve their prognostic significance. The study of Dr. Guignant et al. [10] is a good example of this approach. At day 1-2 of septic shock, a pro-AVP level $>110 \mathrm{pmol} / \mathrm{l}$ associated with a pro-ADM level $>5 \mathrm{nmol} / \mathrm{l}$ predicted early mortality with a better accuracy than SAPS II or SOFA scores. Among others, the early prognostic assessment is important because the severity of the disease influences the consumption of health-care resources and the indication for intensive care unit admission, both able to influence prognosis. Used in conjunction with clinical assessment, biomarkers may therefore be useful for optimized care of septic patients. However, the additional value of these combinations when compared with scoring systems has to be further evaluated in order to translate their measurement into clinical practice.

In summary, the study of Guignant et al. [10] clearly suggests an increased secretion of both pro-AVP and pro-ADM during septic shock. Like for other promising biomarkers, their production is correlated with prognosis. However, it remains to be evaluated if their production is inadequately upregulated or if it reflects an adaptative response to shock that could be even insufficient. Like cortisol, AVP and ADM partly reflect the level of stress of the organism, and it has been established that a relative cortisol insufficiency is better correlated with prognosis during sepsis than its increase [15]. The study of Guignant et al. [10] is an observational study and does not allow drawing any conclusion concerning therapeutic interventions. However, the observed correlation between the pro-AVP or pro-ADM level and prognosis in septic shock patients highlights the interest in studying AVP and ADM as potential therapeutic targets in future research.

\section{References}

1. Itoi K, Jiang YQ, Iwasaki Y, Watson SJ (2004) Regulatory mechanisms of corticotropin-releasing hormone and vasopressin gene expression in the hypothalamus. J Neuroendocrinol 16:348-355

2. Sharshar T, Blanchard A, Paillard M, Raphael JC, Gajdos P, Annane D (2003) Circulating vasopressin levels in septic shock. Crit Care Med 31:1752-1758

3. Landry DW, Levin HR, Gallant EM, Ashton RC Jr, Seo S, D'Alessandro D, Oz MC, Oliver JA (1997) Vasopressin deficiency contributes to the vasodilation of septic shock. Circulation 95:1122-1125

4. Seligman R, Papassotiriou J, Morgenthaler NG, Meisner M, Teixeira PJ (2008) Copeptin, a novel prognostic biomarker in ventilator-associated pneumonia. Crit Care 12:R11
5. Krüger S, Papassotiriou J, Marre R, Richter K, Schumann C, von Baum H, Morgenthaler NG, Suttorp N, Welte T, CAPNETZ Study Group (2007)

Pro-atrial natriuretic peptide and pro-vasopressin to predict severity and prognosis in community-acquired pneumonia: results from the German competence network CAPNETZ. Intensive Care Med 33:2069-2078

6. Hinson JP, Kapas S, Smith DM (2000) Adrenomedullin, a multifunctional regulatory peptide. Endocr Rev 21:138167

7. Hirata Y, Mitaka C, Sato K, Nagura T, Tsunoda Y, Amaha K, Marumo F (1996) Increased circulating adrenomedullin, a novel vasodilatory peptide, in sepsis. J Clin Endocrinol Metab 81:1449-1453
8. Christ-Crain M, Morgenthaler NG, Struck J, Harbarth S, Bergmann A, Müller B (2005) Mid-regional proadrenomedullin as a prognostic marker in sepsis: an observational study. Crit Care 9:R816-R824

9. Shoji H, Minamino N, Kangawa K, Matsuo H (1995) Endotoxin markedly elevates plasma concentration and gene transcription of adrenomedullin in rat. Biochem Biophys Res Commun 215:531-537

10. Guignant $C$, Voirin $N$, Venet $F$, Poitevin F, Malcus C, Bohé J, Lepape A, Monneret G (2009) Assessment of pro-vasopressin and proadrenomedullin as predictors of 28-day mortality in septic shock patients. Intensive Care Med doi: 10.1007/s00134-009-1610-5 
11. Jochberger S, Dörler J, Luckner G, Mayr VD, Wenzel V, Ulmer H, Morgenthaler NG, Hasibeder WR, Dünser MW (2009) The vasopressin and copeptin response to infection, severe sepsis, and septic shock. Crit Care Med 37:476-482

12. Jensen JU, Heslet L, Jensen TH, Espersen K, Steffensen P, Tvede M (2006) Procalcitonin increase in early identification of critically ill patients at high risk of mortality. Crit Care Med 34:2596-2602
13. Morgenthaler NG, Struck J, Christ-Crain M, Bergmann A, Müller B (2005) Proatrial natriuretic peptide is a prognostic marker in sepsis, similar to the APACHE II score: an observational study.

Crit Care 9:R37-R45

14. Roch A, Allardet-Servent J, Michelet P, Oddoze C, Forel JM, Barrau K, Loundou A, Perrin G, Auffray JP, Portugal H, Papazian L (2005) $\mathrm{NH}_{2}$ terminal pro-brain natriuretic peptide plasma level as an early marker of prognosis and cardiac dysfunction in septic shock patients. Crit Care Med 33:1001-1007
15. Annane D, Sébille V, Troché G, Raphaël JC, Gajdos P, Bellissant E (2000) A 3-level prognostic classification in septic shock based on cortisol levels and cortisol response to corticotropin. JAMA 283:1038-1045 